\title{
Encefalopatía hiperamoniémica secundaria a infección urinaria por germen productor de ureasa. Caso clínico pediátrico
}

\author{
Hyperammonemic encephalopathy due to urinary tract infection by urea \\ splitting bacteria. A pediatric case report
}

\author{
Dra. Pamela Acosta ${ }^{a}$, Dr. Manuel Nogueira ${ }^{a}$, Dra. Rosario Gallagher ${ }^{b}$,Dra. Cecilia Waquima, \\ Dr. Ignacio Piroli ${ }^{a}$ Dr. Rodrigo Carmona ${ }^{b}$, Dra. Mónica Centeno y Dr. Eduardo Motto ${ }^{b}$
}

\section{RESUMEN}

El incremento del amonio en sangre, hiperamoniemia, es pasible de provocar compromiso neurológico al atravesar la barrera hematoencefálica. La causa más frecuente y conocida de hiperamoniemia es la alteración en la función hepática. Sin embargo, se deben considerar otras patologías, de menor frecuencia y poco conocidas. La infección del tracto urinario por gérmenes productores de ureasa debe ser contemplada a pesar de ser infrecuente en pediatría.

Se reporta el caso de un niño con encefalopatía aguda grave, con niveles elevados de amonio en sangre, en quien, luego de descartar otros diagnósticos diferenciales, se asumió el cuadro comohiperamoniemia secundaria a infección del tracto urinario por Corynebacterium riegelii, un germen productor de ureasa. Se implementaron medidas generales de tratamiento para la encefalopatía hiperamoniémica y tratamiento antibiótico específico, con buena evolución el paciente.

Palabras clave: encefalopatía, hiperamoniemia, germen productor de ureasa, pediatría.

\begin{abstract}
Elevated level of ammonia in the blood, defined as hyperammonemia, is feasible to cause neurological symptoms when crossing the blood-brain barrier. The most frequent and studied cause of hyperammonemia is liver failure. Nevertheless, other less frequent and known etiologies must be considered. Urinary tract infection caused by urea-splitting bacteria, despite being unusual in pediatric patients, must be taken into account. We report a pediatric patient with severe acute encephalopathy and high levels of ammonia in blood. After ruling out other causes of hyperammonemia, it was assumed secondary to urinary tract infection by Corynebacterium riegelii, a ureasplitting bacteria. General treatment for hyperammonemic encephalopathy was established, as well as specific treatment with antibiotics. The patient evolved favorably.

Key words: encephalopathy, hyperammonemia, urea-splitting bacteria, pediatrics.
\end{abstract}

a. Terapia Intensiva Pediátrica, Hospital de Pediatría "Prof. Dr. Juan P. Garrahan",

Ciudad Autónoma de Buenos Aires.

b. Unidad de Cuidados Intensivos Pediátricos 44, Hospital de Pediatría "Prof. Dr. Juan P. Garrahan", Ciudad Autónoma de Buenos Aires.

Correspondencia:

Dra. Pamela Acosta: pameacosta@hotmail.com

Financiamiento: Ninguno.

Conflicto de intereses: Ninguno que declarar.

Recibido: 11-3-2017

Aceptado: 14-6-2017 http: / / dx.doi.org/ 10.5546/ aap.2017.e454

Cómo citar: Acosta P, Nogueira M, Gallagher R, et al. Encefalopatía hiperamoniémica secundaria a infección urinaria por germen productor de ureasa. Caso clínico pediátrico. Arch Argent Pediatr 2017;115(6):e454-e457.

\section{INTRODUCCIÓN}

La hiperamoniemia, definida como la presencia de un nivel elevado de amonio en sangre, puede causar, al atravesar la barrera hematoencefálica, distintos niveles de compromiso neurológico, como letargo, irritabilidad y, en los casos más graves, convulsiones y coma. ${ }^{1}$

Diferentes enfermedades congénitas y adquiridas desarrollan hiperamoniemia, entre ellas, la más frecuente es la cirrosis hepática con cortocircuito portosistémico. Otras causas son hemorragia digestiva, fístula vesicorrectal, mieloma múltiple, leucemia, errores congénitos del metabolismo, acidosis tubular renal distal, síndrome de Reye, nutrición parenteral, shock y drogas, como el ácido valproico, los barbitúricos y la asparaginasa. ${ }^{1-3}$

La infección urinaria por gérmenes productores de ureasa constituye también una causa de hiperamoniemia, que es una condición patológica poco frecuente y de incidencia desconocida. ${ }^{2}$

En este caso, se presenta a un paciente pediátrico con encefalopatía hiperamoniémica secundaria a infección urinaria por Corynebacterium riegelii.

\section{CASO CLÍNICO}

Paciente de 2 años y 3 meses, de sexo masculino, que consultó por vómitos y decaimiento de 24 horas de evolución.

Presentó como antecedentes malformación anorrectal, ano imperforado y fístula rectovesical corregida quirúrgicamente mediante técnica de Peña en el año 2015 y posterior cierre de colostomía en 2016. Otras malformaciones 
presentes: riñón en herradura, hipospadia subcoronal y ureterohidronefrosis derecha. Debido a esta última afección, recibió tratamiento profiláctico con cefalexina.

Fue evaluado en el Servicio de Emergencias en regular estado general, afebril. Se observó, en el examen físico, taquicardia y tendencia al sueño. Presentó un episodio convulsivo con retrodesviación de la mirada, hipertonía generalizada, deterioro del sensorio y coma, por lo que requirió intubación endotraqueal y asistencia respiratoria mecánica.

Se realizaron exámenes de laboratorio en sangre, orina y líquido cefalorraquídeo (LCR), y resultaron patológicos los siguientes:

- Hemograma con leucocitosis con predominio neutrofílico, 23400 leucocitos $/ \mathrm{mm}^{3}$ con $84 \%$ de neutrófilos.

- Amonio de $450 \mathrm{mg} / \mathrm{dl}$ (valor normal -VN-: 20-120 mg/dl).

- Sedimento urinario patológico: amarillo, turbio, pH 9, densidad 1010, esterasa leucocitaria +++ , leucocitos en regular cantidad, piocitos en regular cantidad.

La función renal, hepatograma, ionograma, glucemia y citoquímico de LCR resultaron normales. Se obtuvieron muestras para 2 hemocultivos, urocultivo y cultivo de LCR.

Se realizaron los siguientes estudios complementarios:

- Electroencefalograma, que se informó enlentecido, sin focos ni paroxismos.

- Tomografía de cerebro simple, sin imágenes patológicas.

- Ecografía abdominal y renal, que informó una dilatación ureteropielocalicial y abundantes ecos móviles en toda la vía urinaria.

Se realizó una interconsulta con el Servicio de Errores Congénitos del Metabolismo y se envió una muestra de orina para el estudio de ácidos orgánicos urinarios y acilcarnitinas.

Se indicó tratamiento antibiótico con $300 \mathrm{mg} /$ $\mathrm{kg} /$ día de piperacilina-tazobactam endovenosa y $60 \mathrm{mg} / \mathrm{kg} /$ día de aciclovir endovenoso, que cubrían focos meníngeo y urinario, $5 \mathrm{mg} / \mathrm{kg} /$ día de difenilhidantoína endovenosa como anticonvulsivante y medidas destinadas a disminuir los niveles de amonio, que incluían neomicina, catárticos y $250 \mathrm{mg} / \mathrm{kg} /$ día de benzoato de sodio endovenoso.

A las 24 horas del ingreso, con franco descenso de la amoniemia y mejoría del sensorio, se logró su extubación con evolución favorable.

El urocultivo resultó positivo para
Corynebacterium riegelii como germen único con recuento de 100000 unidades formadoras de colonias (UFC). Los demás cultivos fueron negativos y los estudios metabólicos solicitados se informaron con valores dentro de los límites normales.

Se realizó un tratamiento antibiótico durante 14 días para la infección urinaria y, posteriormente, fue dado de alta luego de 5 días de internación en la Unidad de Cuidados Intensivos (UCI) más 6 días en Sala de Pediatría, sin complicaciones, con recuperación neurológica completa.

\section{DISCUSIÓN}

La hiperamoniemia tiene etiología multifactorial y, en general, son tres los mecanismos involucrados: sobrecarga de amonio en la circulación portal en un hígado normofuncionante, derivación del amonio a nivel hepático y alteraciones de su metabolismo. ${ }^{3}$

El amonio es un producto tóxico derivado del complejo metabolismo proteico, en el que se encuentran involucrados diferentes órganos. Aproximadamente, el $80 \%$ del nitrógeno es excretado como urea formada en el hígado. La serie de reacciones bioquímicas que generan urea son conocidas como ciclo de Krebs-Henseleit y ocurren en el citosol y en las mitocondrias. Finalmente, la urea es excretada por el riñón. ${ }^{3}$

Como en el caso presentado, frente a una infección urinaria por germen productor de ureasa, los niveles de amonio urinario pueden aumentar y alcanzar la circulación sistémica con el consiguiente riesgo de encefalopatía. Proteus mirabilis y Pseudomona aeruginosa son las bacterias productoras de ureasa más reconocidas; sin embargo, especies de Klebsiella, Morganella morganii y corinebacterias también pueden producir ureasa, la cual hidroliza la urea en amoníaco $\left(\mathrm{NH}_{3}\right)$ y dióxido de carbono. El amoníaco se combina con iones de hidrógeno y forman amonio $\left(\mathrm{NH}_{4}\right)$, que resulta en la alcalinización de la orina. El amoníaco es una base débil en equilibro con el amonio, en una reacción con un pKa de 9,15. Esto implica que, en un $\mathrm{pH}$ urinario elevado, los niveles de amoníaco aumentan de modo significativo. Este se difunde con facilidad por la membrana celular debido a su neutralidad eléctrica y liposolubilidad. Una vez en el torrente sanguíneo, el amoníaco es nuevamente convertido en amonio hidrosoluble, incapaz de difundirse a la orina. ${ }^{3}$

Se ha sugerido, en varios reportes de casos, que la absorción sistémica del amoníaco 
producido por estas bacterias se produciría solo en casos de obstrucción o estasis del flujo urinario. La distensión vesical resultante aumentaría la superficie de difusión y facilitaría la absorción. ${ }^{3}$

La hiperamoniemia se asocia a diversos efectos deletéreos, de los cuales el edema cerebral y la hipertensión endocraneana asociada son los más graves. ${ }^{4}$ Puede presentarse con un amplio espectro de síntomas, los cuales incluyen alteraciones del ánimo y la personalidad, disfunciones cognitivas, ataxia, convulsiones y alteraciones del nivel de conciencia desde somnolencia hasta coma y muerte. ${ }^{3}$ La gravedad de los síntomas dependerá de la etiología, de los niveles de amonio en sangre, de la velocidad de instauración y de la edad del paciente. ${ }^{3}$

En la encefalopatía hiperamoniémica, la lesión característica es el edema cerebral citotóxico de predominio astrocitario. Cuando altas concentraciones de amonio llegan al sistema nervioso central, los astrocitos y las neuronas lo captan para su metabolización a glutamina a través de un proceso de aminación dependiente de adenosin trifosfato (ATP) que eleva las concentraciones citoplasmáticas de glutamina en las células y este aminoácido se comporta como una molécula osmóticamente activa que induce la entrada de agua a la célula y genera lesión osmótica. ${ }^{5}$

El amonio también está implicado en alteraciones de la neurotransmisión dependiente del ácido gamma aminobutírico (Gammaaminobutyric acid; GABA, por sus siglas en inglés), lo que desencadena un aumento de la actividad inhibitoria de este sistema, tanto por efectos directos de interacción con el receptor GABA como por un aumento de la sensibilidad del receptor a otros agonistas, como las benzodiacepinas y la glicina. ${ }^{6}$

Respecto del germen responsable en el caso clínico presentado, las corinebacterias están ampliamente distribuidas en el ambiente como habitantes de la tierra y el agua. Son colonizantes de piel y mucosas de humanos y otras especies animales. ${ }^{7}$ Exceptuando Corynebacterium diphtheriae, las demás especies, raramente, causan infecciones en los humanos; sin embargo, se han reportado infecciones oportunistas tanto en pacientes inmunocomprometidos como inmunocompetentes. ${ }^{8}$

Corynebacterium riegelii, una especie recientemente descrita, fue aislada por primera vez por Funke et al. en el año 1998, en urocultivos de pacientes femeninas con infecciones urinarias. ${ }^{8}$
Se caracteriza, de manera principal, por su gran capacidad ureásica y por fermentar la maltosa, pero no la glucosa, propiedad prácticamente exclusiva de $C$. riegelii y que no se da en ninguna otra especie del género ni en otros géneros de bacilos Gram-positivos. En su identificación, se deberá plantear, sobre todo, un diagnóstico diferencial con otro Corynebacterium patógeno del tracto urinario, el Corynebacterium urealyticum, con el que comparten diversas características fenotípicas: crecimiento lento, reacción de la catalasa positiva, potente capacidad para desdoblar la urea y pequeño tamaño en la tinción de Gram. No obstante, se diferencian en que, mientras $C$. riegelii no es lipofílico, presenta metabolismo fermentativo sobre la maltosa y es sensible a la mayoría de antibióticos, C. urealyticum es lipofílico, no fermentativo y multirresistente. ${ }^{9}$

Entre los diagnósticos diferenciales de encefalopatía aguda, se debe tener en cuenta la encefalopatía hiperamoniémica y considerar la infección urinaria por germen productor de ureasa como su etiología posible, junto con otras causas más frecuentes.

El diagnóstico precoz y, consecuentemente, el tratamiento adecuado y temprano se traducirán en una evolución y pronóstico más favorables.

Además, las corinebacterias aisladas en muestras de orina, incluso como germen único, son, muchas veces, consideradas contaminantes. Se debe tener presente que Corynebacterium riegelii puede ser causante de infecciones urinarias graves. Por lo tanto, se destaca la importancia de considerarlo como probable patógeno responsable frente a su identificación en el urocultivo, siempre que el contexto clínico y demás exámenes de laboratorio lo acompañen.

\section{REFERENCIAS}

1. Miyauchi R, Matsuda $Y$, Tokuda Y. Urinary tract infection as a case of hyperammonemic encephalopathy. General Medicine 2015;16(2):95-8.

2. Kenzaka T, Kato K, Kitao A, et.al. Hyperammonemia in Urinary Tract Infections. Plos One 2015;10(8):e0136220.

3. Albersen M, Joniau S, Van Poppel H, et. al. Urea splitting urinary tract infection contributing to hyperammonemic encephalopathy. Nat Clin Pract Urol 2007;4(8):455-8.

4. Carrillo Esper R, Noriega Iriondo M, Sánchez García R. Amonioe hiperamonemia.Su significado clinico. Rev Invest med Sur Mex 2008;15(3):209-13.

5. Lockwood A, McDonald J, Rieman R, et al. The dynamics of ammonia metabolism in man: Effects of liver disease and hyperammonemia. J Clin Invest 1979;63(3):449-60.

6. Yurdaydin C, Walsh TJ, Engler H, et al. Gut bacteria provide precursors of benzodiazepine receptor ligands in a rat model of hepatic encephalopathy. Brain Res 1995;679(1):42-8. 
7. Matusnami M, Otsuka Y, Ohkusu K, et. al. Urosepsis caused by Globicatella sanguinis and Corynebacterium riegelii in an adult. Case report and literature review. J Infect Chemother 2012;18(4):552-4.

8. Aygun G, Midili K, Cilingir H, et. al. A Fatal case of
Urosepsis Due to Corynebacterium Riegelii. BrazJMicrobiol 2013;44(2):475-6.

9. Verdaguer R, Tubau F, Vazquez Z, et. al. Infeccion del tracto urinario causada por Corynebacterium Riegelii. Enferm Infecc Microbiol Clin 2008;26(10):669-70. 